\title{
Product Model Based Multiple Viewpoint Information Sharing Using Features Technology
}

\author{
J.O. CANCIGLIERI ${ }^{1}$ and R.I.M. YOUNG ${ }^{2}$ \\ 'Pontificia Universidade Católica do Paraná - LAS Laboratory of Automation and Systems - \\ Rua Imaculada Conceição, 1155 - Prado Velho - Curitiba - PR-Brazil - CEP 80215-030-e - \\ mail: osiris@ rla01.pucpr.br. \\ ${ }^{2}$ Wolfson School of Mechanical and Manufacturing Engineering - Loughborough University - \\ Loughborough, Leicestershire-LEII3TUUK-e-mail:R.I.Young@lboro.ac.uk.
}

\begin{abstract}
Concurrent engineering is an important philosophy in achieving better time to market in new product development. While the use of design teams is achieving some success there is a need for modern software tools which support the design process to be radically improved. This paper provides a contribution in the area of decision support systems based on the use of product and manufacturing models to provide appropriate information. Typically design for manufacture systems provide only support for one process e.g. design for assembly, design for machining. However, when the full breadth of design for manufacture is considered there are many aspects which must be addressed. This leads to the need for information systems to be able to support multiple views of a product, where each view provides the appropriate representation to support one manufacturing perspective. This paper discusses the requirements of a reasoning system which is able to provide multiple views of a product and which can provide mechanisms to move from one viewpoint to another. The research focuses on injection moulding and considers viewpoints such as product functionality, product mouldability, mould design elements and mould manufacturing viewpoints. A case study product is discussed to illustrate the approach being used.
\end{abstract}

Key words: Concurrent Engineering, Features Technology, Machining, Product Modelling and Product Mouldability, Design For Manufacture.

The original version of this chapter was revised: The copyright line was incorrect. This has been corrected. The Erratum to this chapter is available at DOI: 10.1007/978-0-387-35637-2_11 


\section{INTRODUCTION}

A crucial problem in the development of new products is to reduce the time required for their design and manufacture while still maintaining high quality and minimum development cost. To achieve this inputs are needed from experts in a multitude of disciplines as well as from customers and suppliers. The overall design process must be well orchestrated and integrated. Hence the interest in recent years in Concurrent Engineering.

Concurrent engineering is an important philosophy in achieving better time to market in new product development. However, while the use of design teams is achieving some success, there is a need for the software tools which support the design process to be radically improved. One important aspect of Concurrent Engineering is Design For Manufacture (DFM). This recognises that a company cannot meet quality and cost objectives with isolated design and manufacturing engineering operations. Thus, the DFM approach embodies underlying manufacturing imperatives that help to maintain communication between all components of the manufacturing system and enables the design to be adapted during each stage of product realisation (Boothroyd et al. 1993). Other imperatives include a general attitude that resists making irreversible design decisions before they absolutely must be made and a commitment to the continuous optimisation of products and their manufacturing processes. Therefore, the objectives of the design for manufacture approach are to identify product concepts that are inherently easy to manufacture, to focus on component design for ease of manufacture and assembly, and to integrate manufacturing process design and product design to ensure the best matching of needs and requirements.

Design systems should integrate Design, Manufacturing, database and expert systems tools (Willems et.al. 1995). Such systems should aim to assist concurrent engineering teams by providing access to consistent sources of product and manufacturing information, and providing applications that support decision making.

Feature technology has been expected to provide a better approach to the integration of design and the manufacturing activities following design such as engineering analysis, process planning, machining, fixturing, etc. (Salomons et.al. 1993). However, researchers have explored the use of features technology with only limited success. Typically, features have been used to represent one design or manufacturing viewpoint e.g. form, machining, assembly, etc. To be successful, integrated software systems must link a range of different views of products e.g. geometric view, functionality view, mouldability view, manufacturing view and so on. Current approaches are incapable of meeting these needs (Allada, and Anand 1995). 
This paper explores the potential of utilising features based approaches in combination with information modelling techniques to provide comprehensive sets of information which can support a range of manufacturing viewpoints. Each information set can be seen as supporting one aspect of decision making and will refer to aspects of form or other attributes of a part. These sets can be used in reasoning about the design, or performance in manufacturing the part.

This paper provides a contribution in the area of decision support systems based on the use of product and manufacturing models to provide appropriate information. Also, It proposes a reasoning system structure which can cope with the interactions between different views of the product i.e. product manufacture, product design, product mouldability, mould design and mould manufacture.

\section{MULTIPLE VIEW DESIGN AND MANUFACTURING}

Design for Manufacture software systems of the future must provide support for multiple processes, because design for manufacture involves considerations of many different perspectives of the product, so it is increasingly necessary to balance and integrate work with multiple views (or perspectives) of the product. This view is supported by the work of (Rosenman and Gero 1996) who have explored a multiple view approach in architectural design.

One of the approaches to multiple view design for manufacturing is based on the use of agent systems. Agent systems have been defined differently by researchers, but definitions which are suitable in this context are "the agent system is viewed as a system capable of general intelligent action" or it is a "type of knowledge-base system" (Wooldridge and Jennings 1995). However, the communications or translation of information between distinct domains still causes a problem due to the diversity of types of information involved in a multiple view environment.

The development of design for manufacture applications has, typically, been focused only on single manufacturing viewpoints (Gupta et. al.1997, Krause et al 1995, Boothroyd 1994 and Fauvel 1994). For example, (Gupta et al. 1997 and Sanchez et al. 1997) approaches design for manufacture solely from the machining perspective and (Boothroyd 1994) concentrates on design for assembly. From these types of work it can be seen that each view taken requires its own structure of product information. Furthermore, the structuring of the product information is similar to the structuring 
pursued in the area of features technology, e.g. machining, assembly, fixturing features and so on.

Product Modelling is another important aspect of research involving the development of CAE systems. It has been recognised by both research and application communities over the past several years that an advanced information system is needed to integrate and co-ordinate the various lifecycle considerations during product realisation (Krause et al. 1993). For more than a decade, the International Organization for Standardization (ISO) has been working on developing the STEP standard which is strongly focused on data exchange (between systems).

It is also important for Product Models in the future to be able to deal with multiple view representations of the product. An important aspect of research into information driven CAE systems is therefore to develop product models, which can capture different perspectives of the product. This enhanced system functionality can be achieved through the sharing of information related to representations of different aspects of the product in the product model (Fowler 1995). Recently, the STEP community has also recognised that there is the need to share information and integrate different viewpoints of products as evidenced by the work of group WG10 (ISO TC184/SC4/WG10 N219).

Product model research is typically concerned with the definition of the structure of product information, which drives a particular application. The MOSES research, developed between Loughborough and Leeds Universities (UK), has dealt with multiple applications, supporting design for manufacture across machining and injection moulding and also covering applications in design for function and manufacturing planning. However, each of these application areas has been supported by an independent single view of the product. In a multiple viewpoint design and manufacture system such views of the product must be considered to be interdependent. Figure 1 provides a representation of MOSES concept with the overlay, represented by the question marks, of the need to interrelate the information, which supports each application.

This has pursued issues related with multiple viewpoints in a design and manufacturing environment by addressing two related questions:

1. What structure of information in the product model is needed to support different but related views of the product?

2. How can the relationships between these sets of information be defined?

In this work the authors have considered only the relationships between sets of information and they have been targeted at the area of injection 
moulding to provide an appropriate scope for the research. The next section will present the issues related to the area chosen.

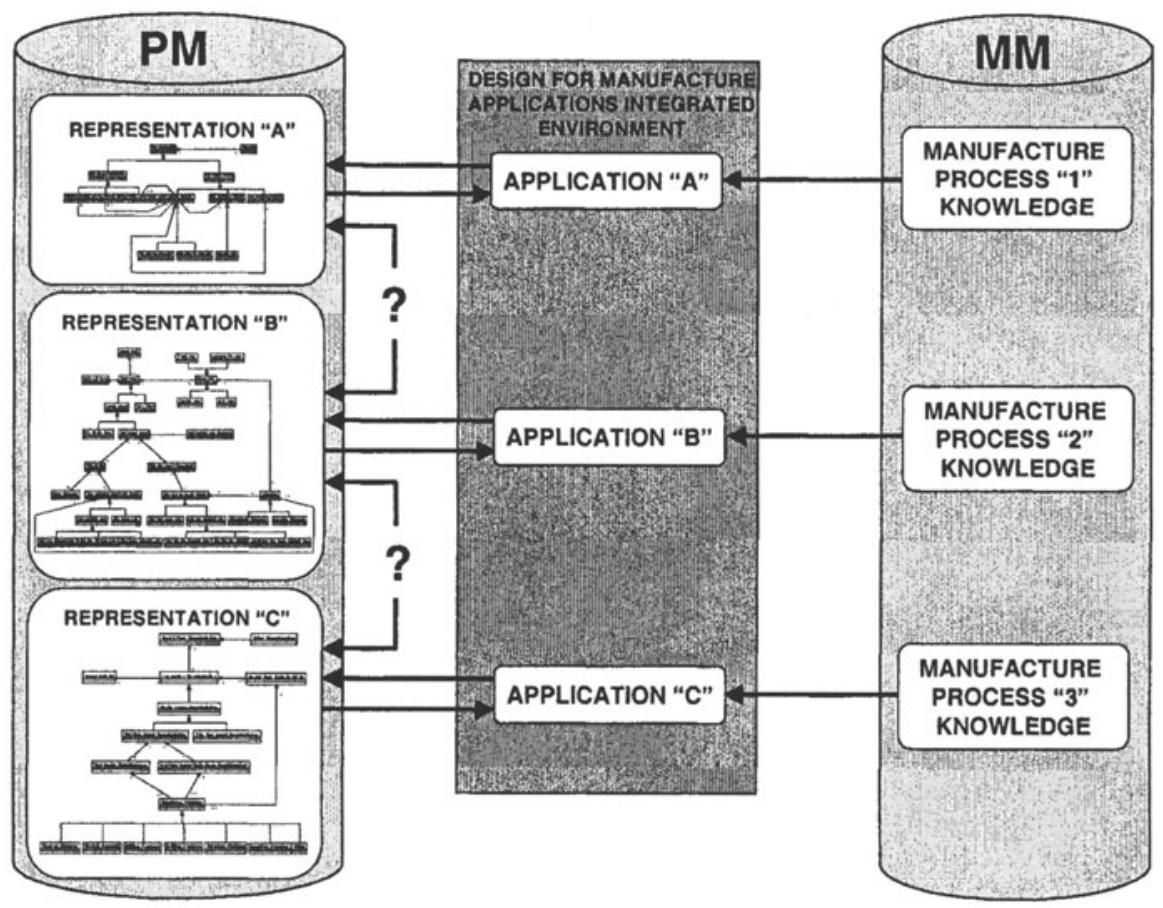

Figure 1. CAE system architecture to support multiple viewpoints.

\subsection{General issues in multiple viewpoints in injection moulding}

Injection moulding is a huge area that covers several expertise sub-areas. This area has opened opportunities for researchers to explore the problems in multiple-view points using basically features technology due to the diverseness and complexity of the issues related with plastic part, mould and manufacturing of them. (Pratt et al. 1993) have developed a knowledge for assessment of the manufacturability and processability of the part. But their research has been constrained only to design the plastic part. (Weinten and Manoochehri 1996) have presented a methodology only for defining the parting line location based on the geometry of the plastic part.

(Chin and Wong 1996) have developed a Knowledge-base system (KSB) for designing plastic products placing emphasis on the conceptual design stage. (Lee et al. 1997) have presented a systematic methodology and knowledge base for injection moulding mould design in a concurrent 
engineering environment. The approach taken is concerned only with the design of the mould. However it does not show how the geometry of the plastic part can be transferred to the mould design.

In the area of CAE systems support for the design of plastic injection moulds, (Ashaab 1994 and Lee 1996) have carried out work at the Department of Manufacturing Engineering of Loughborough University. In the context of MOSES project, (Ashaab 1994) developed the manufacturing model for injection moulding parts which is a common source of welldefined and structured information for supporting decision making in design for manufacture of injection moulding applications. His development provides an initial representation of process capability related to injection moulding.

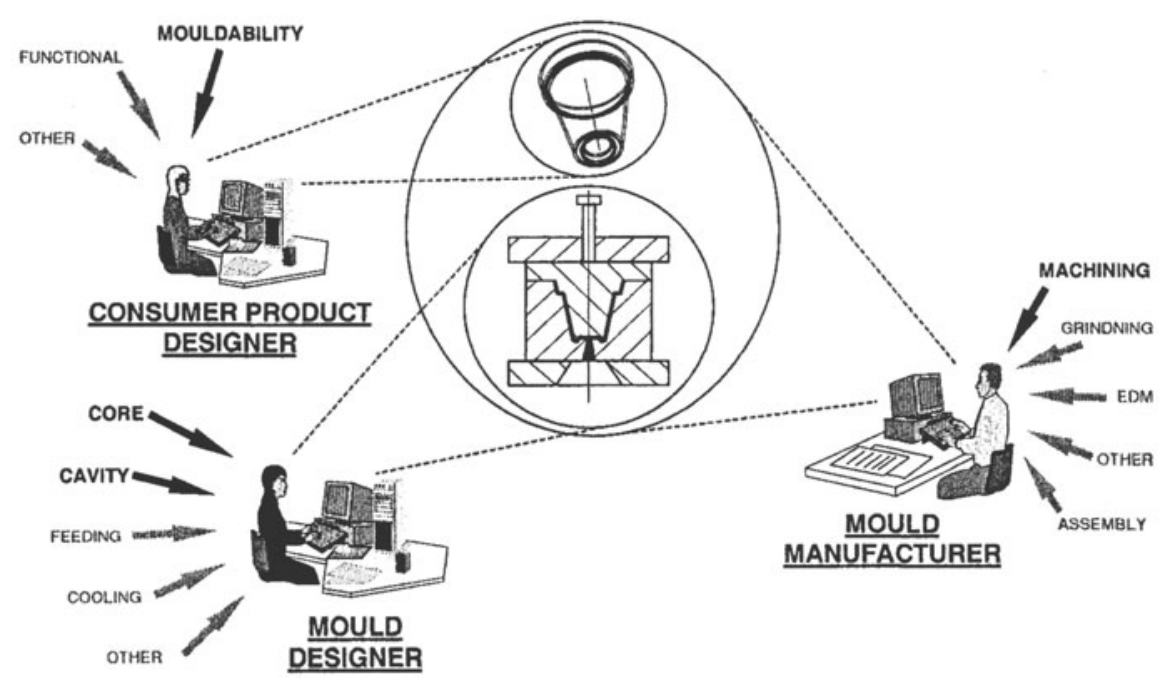

Figure 2. Multiple viewpoints in Injection Moulding.

Moreover, in the MOSES project, (Lee 1996) made an initial exploration with the definition of design for manufacture applications using the Manufacture Model in the Product Model environment. In his development he identified the problem with interactions between mouldability view and core and cavity views in design for manufacture injection moulding. His research was concerned with simple geometric relationships to specify interactions and has only a geometric representation in the product model. The work developed by (Lee 1996) has been used as a key start point to this research. In addition (Lee and Young 1998) have investigated how design for manufacture information can be provided back to design as concurrently as possible. They have identified the necessity to create mechanisms for 
translating information between domains in a concurrent engineering environment.

The research reported in paper has focused on three areas related to injection moulding: the design of a plastic part such as a consumer product, the design of a mould, and the manufacture of the mould to make the consumer product. In these areas there are a number of specific views to be addressed as illustrated in Figure 2. The work reported here concentrates on the interactions between four of them: Mouldability from Consumer product design; Core and Cavity from Mould Design and Machining from Mould Manufacture. The next sections highlight the issues addressed in this research relating two fields identified in section in this section i.e. the structure of information in the product model needed to support different but related views of the product and the definition of the relationships between these sets of information.

\subsection{Product data model}

To deal with multiple views in an injection moulding environment it is necessary to understand that each specific application has to hold an information structure within the product model which is able to support the function of the application. In the Product Data Model there is a need to define data structures, which can support all applications. The product data model representation has been explored for two reasons. Firstly, so it can provide support for its individual area of application and secondly, so it can support the movement of information from one application area to another. The approach taken to explore the product data model structure is not the main focus of this paper.

\subsection{Defining information relationships}

Given that, considered that the data structures have been defined for individual views correctly as highlighted in section 2.1 , the remaining challenge is to understand how the information captured in one view can be shaped in a meaningful form for another view during the information transfer process. This research, which has been reported in this article, has explored the understanding of the way that information can be translated between views as also illustrated in Figure 3. This results in an exploration of Translation Mechanisms, which will be discussed more over. 


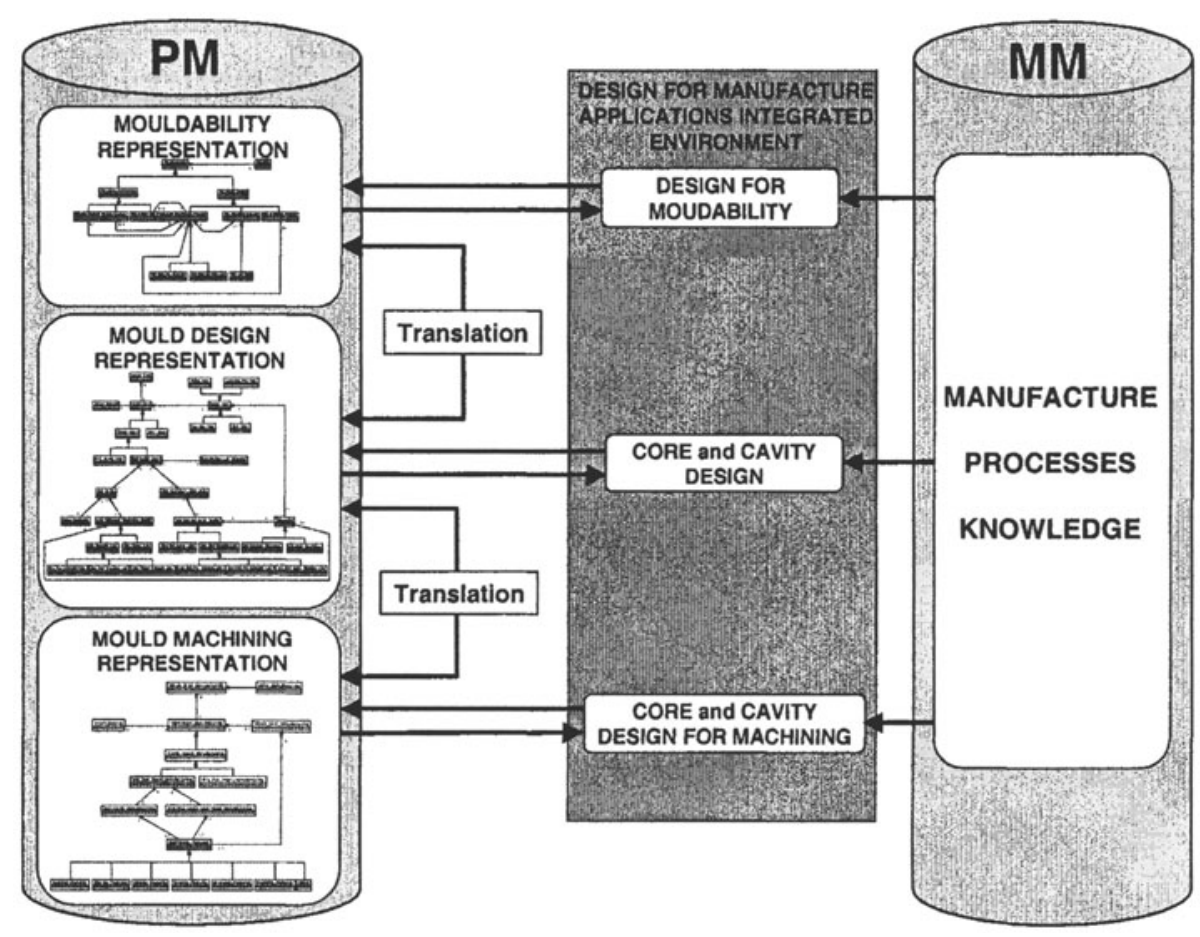

Figure 3. Translation needed to support multiple view approach.

\subsection{Translating information from mouldability view to the mould design view}

This section describes the research performed to define the translation mechanisms that convert information from one view to another. In this research two areas of translation have been explored. The first is the translation mechanisms for converting information from the mouldability view into cavity and core design in the mould design view. The second is the translation mechanisms for converting information from the cavity and core insert design into cavity and core insert manufacturing information in the mould manufacturing view. The mouldability, mould design and mould manufacturing views. Section 2.4.1 conceptually defines the translation mechanisms for translating information between mouldability and mould design views. Section 2.4.2 defines the translation mechanism for converting information between mould design and mould manufacturing views. In both sections the methods used for translating information from one view to another are defined and the translation mechanisms are presented using UML (Unified Modelling Language) language. 


\subsubsection{Critical aspects of information translation between mouldability and mould design views}

There are several aspects to be discussed in terms of translating information between the mouldability view and the cavity and core design in the mould design view. This section discusses the importance of them in the context of what information contained in the mouldability view, needs to be translated for the cavity and core design in the mould design.

Figure 4 highlights the critical information that is necessary for translating from mouldability to cavity and core design. In terms of cavity design translation the critical information is the geometry of the cavity and gate features and their attributes whilst for core design the critical information includes core geometry and ejection features.

The geometric information of the cavity and the core is as it is on geometric shape of the plastic part and the position of the parting line of the mould. Also, the geometry of the cavity and the core are related directly with the shrinkage of the plastic material of the part. The gate and ejection features are also critical because they will affect the mouldability of the plastic part. The following sections will explore each particular critical aspect of translation information between mouldability and cavity and core design in the mould design views. In addition the transformation of the product geometry to accommodate effects of material shrinkage is assumed to have taken place during the design phase. In translating between views the appropriate transformed geometry is extracted from redesigned product in the database. 


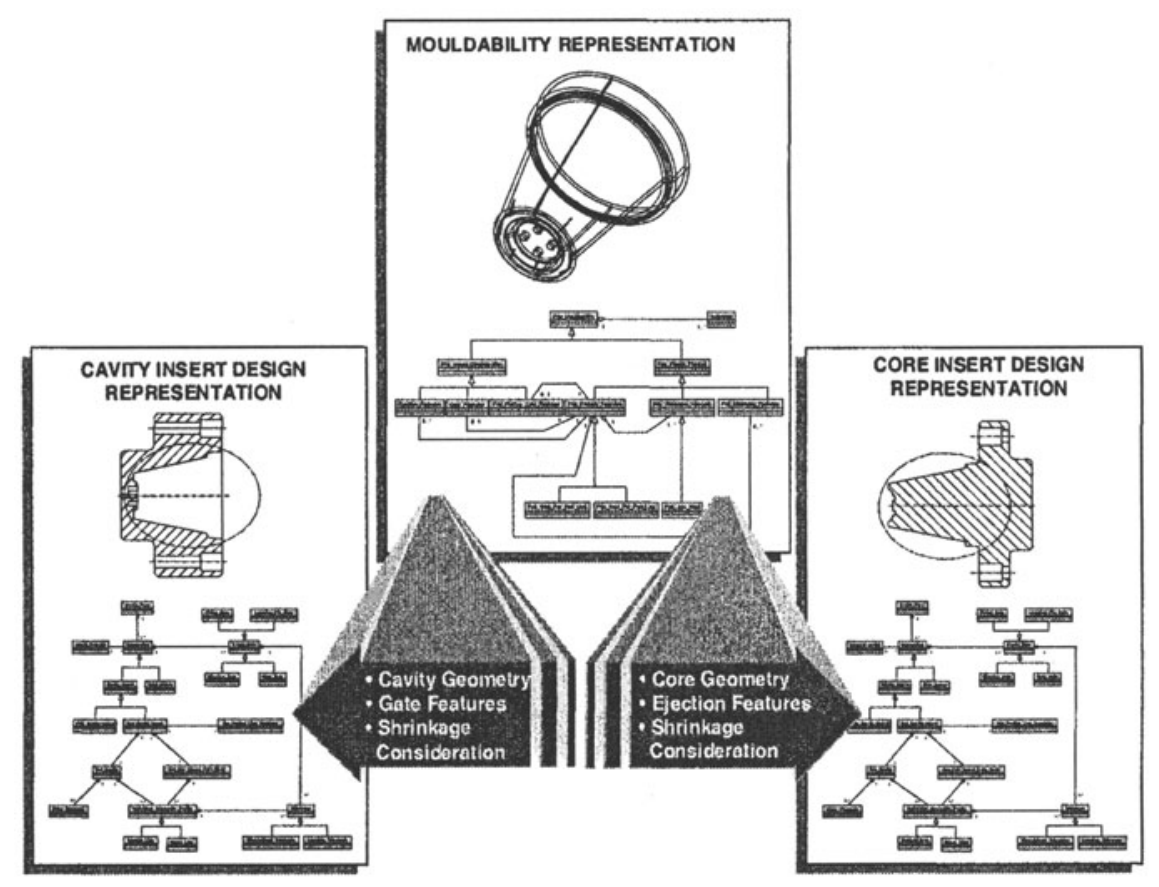

Figure 4. Information to be translated from mouldability view to cavity and core design in the mould design view

\subsubsection{Mouldability primary features to cavity design}

This section explores the mouldability information contained in the primary features and how this is translated to cavity design features in order to generate the main shape of the cavity for the rotational and prismatic walled products. For rotational products the main profile of the cavity is generated by extracting the external profile of each rotational mouldability primary feature that is located below the parting line plane. Figure 5 illustrates how an external profile represented by the rotational mouldability primary features class can be translated as an individual geometric profile (Cav_Taper_Straight_line), which is aggregated by the Rotational Cavity class. The figure shows the external geometric profile information of a rotational wall being re-dimensioned according to the shrinkage coefficient of the material and being translated in terms of the cavity main profile for the cavity insert design. The points $\mathrm{P} 1$ and $\mathrm{P} 2$, and an axis that aggregates the start point and endpoint represent the geometric information of the external profile before considering shrinkage of the material. This profile is illustrated in the figure in grey. The profile illustrated by the point P1' and 
P2', and an axis that aggregates the start point' and endpoint' represent the new geometric definition of the profile which belong to the cavity design in the mould design view after shrinkage consideration. This profile is illustrated in the figure in black colour.

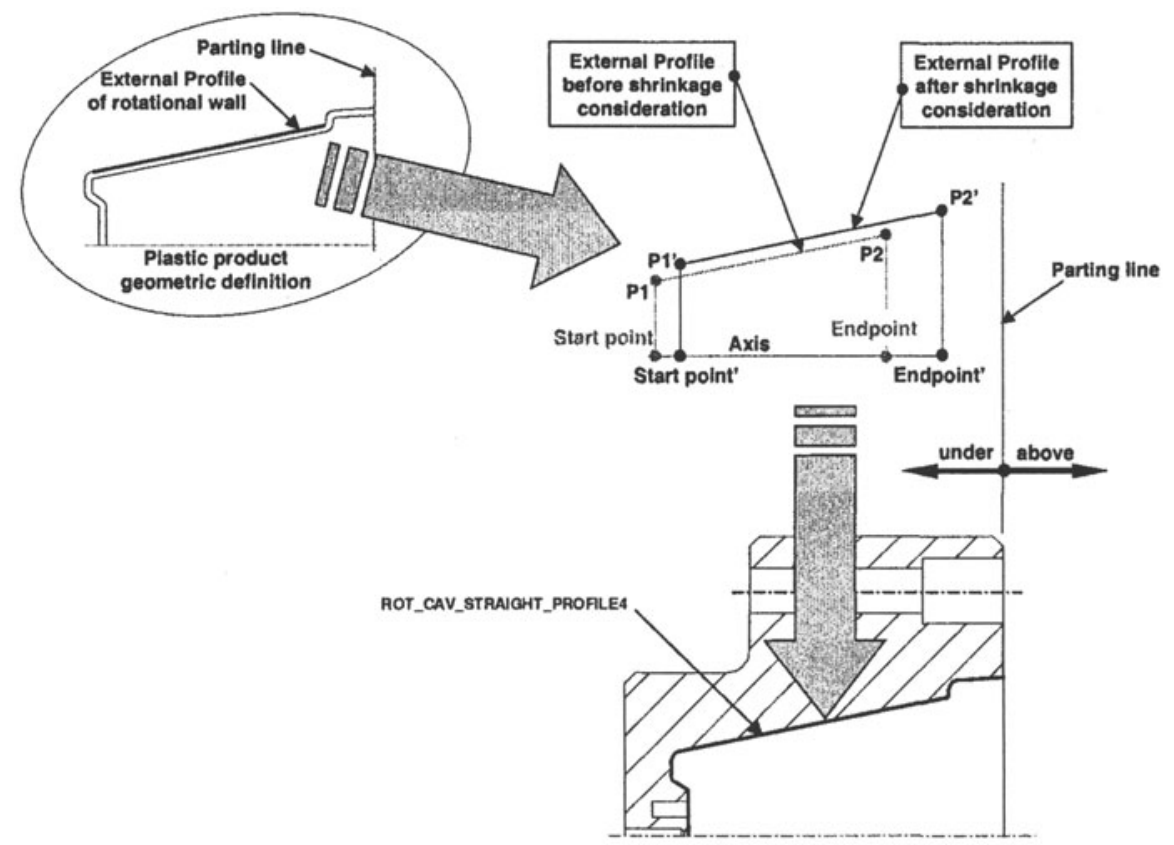

Figure 5. Example of translation of a rotational mouldability primary feature (rotational wall) into rotational cavity design.

The geometric translation of the rotational walls in terms of cavity design is shown in Figure 6. The figure describes the criteria that the translation mechanisms use for translating the geometric information contained in the class Rotational Mouldability Primary Feature (Rot_Primary_Features). The figure "a" shows that "Dia_ext_1" is greater than the value of the "Dia_ext_2" the translation mechanism will get the points P1' and P2', otherwise it will get the points $\mathrm{P} 1$ and $\mathrm{P} 2$ respectively. Also, the figure " $\mathrm{b}$ " shows the criteria used for the translation mechanisms for converting a rotational wall parallel to the parting line into Cavity Straight Line profile. 
(a) Translation of the geometry of a rotational wall perpendicular to the parting line

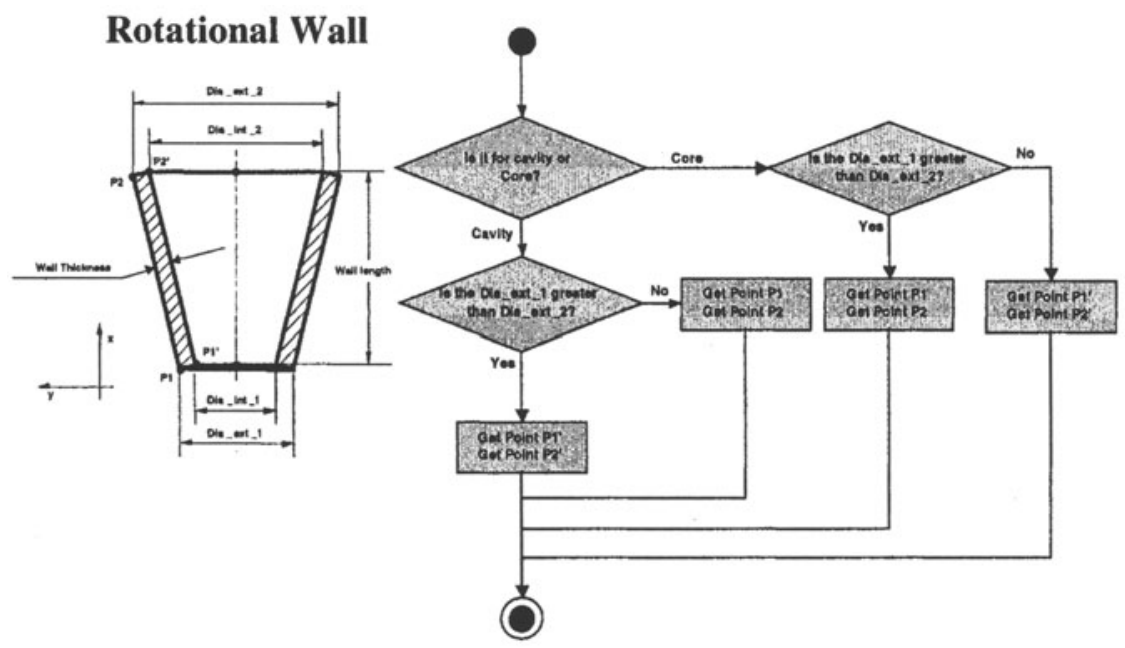

(b) Translation of the geometry of a rotational wall parallel to the parting line
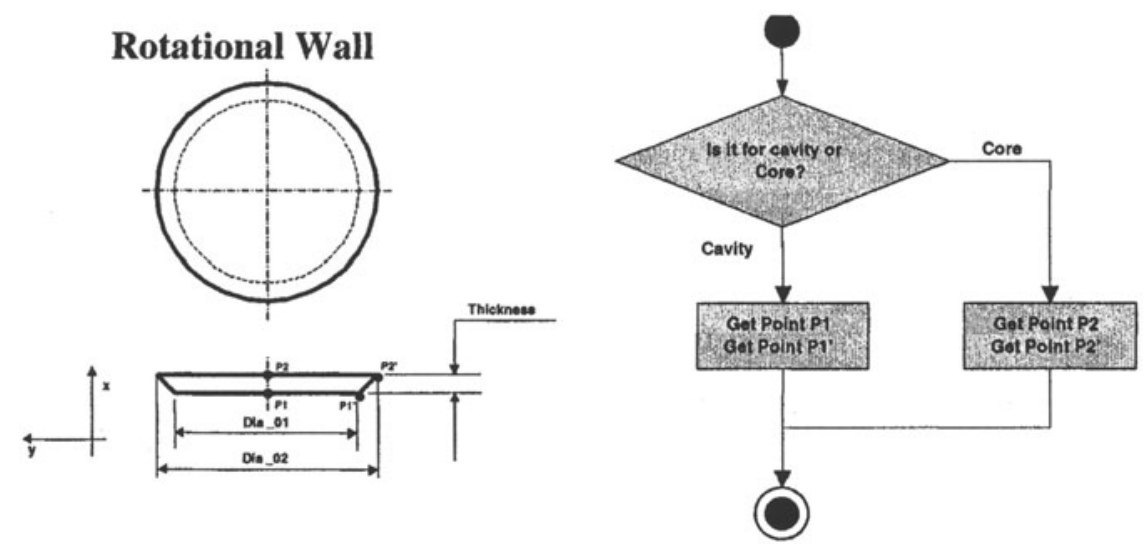

Figure 6. Geometric translation of the Rotational Mouldability Primary Features.

Similarly, to generate the main shape of the prismatic cavity it is necessary to extract the external surface of each prismatic mouldability primary feature that is located under the parting line plane. Figure 7 illustrates the external plane surface of the Prismatic Mouldability Primary Features class being translated as an individual geometric surface 
(Cav_Per_Plane_Surf) of the Prismatic Cavity class. The figure explores the external geometric surface of a prismatic wall being re-dimensioned according to the shrinkage coefficient of the material and being translated in terms of cavity shape in the cavity insert. The surface highlighted in the figure aggregates four points P1, P2, P3 and P4 before the shrinkage of material has been considered. After the shrinkage consideration the surface increased its size and translating the points P1, P2, P3 and P4 into P1', P2', P3' and P4' respectively.

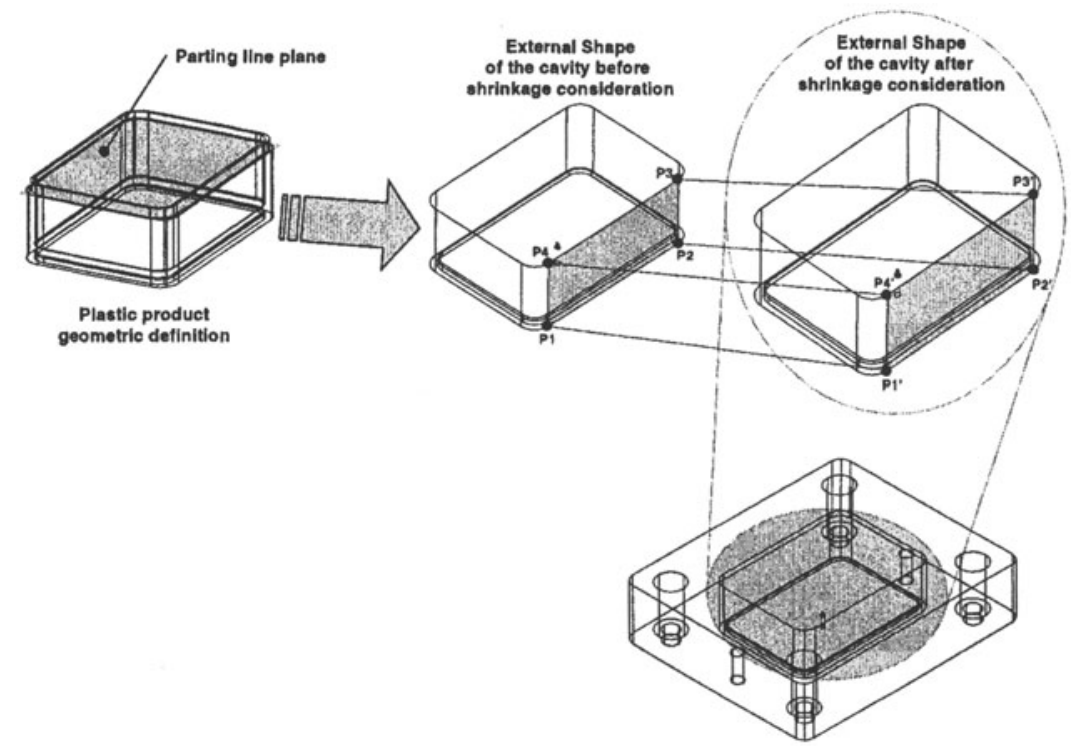

Figure 7. Example of translation of a prismatic mouldability primary feature (plane wall) into prismatic cavity design.

As described previously, each primary mouldability feature must be translated in terms of cavity design. After the plastic product has been resized, it is necessary to convert each feature into cavity and core design features in the mould design view. For rotational products it is necessary to extract geometric information from the external profile of each rotational primary and transition feature in order to generate the main profile of the cavity with its attributes and associated objects. 
The steps of the translation process for modelling the rotational cavity design representation from the rotational plastic product information contained in the mouldability are:

i) to search the wall mouldability information;

ii) to get the specific external profile with its associated objects and store the information in the right form in the database;

iii) to match the information contained in the extracted profiles regarding with the respective cavity profile that is defined in the mould design view.

These steps are illustrated in Figure 5 by considering the external profile of the wall and examining the co-ordinate values of the point $\mathrm{P} 1(\mathrm{y})$ and P2(y), defined by two distinct points P1 and P2. In this case this profile will be translated as a Cavity Taper Straight Line (Cav_Taper_Straight_Line) in the cavity design view. However if the value of the P1(y) has the same value of the value of the P2(y), it has to be translated as a Cavity Parallel Straight Line (Cav_Par_Straight_Line).

In both of the above cases the values of the co-ordinates of the points $\mathrm{P} 1(\mathrm{x})$ and $\mathrm{P} 2(\mathrm{x})$ must be different. The same approach can be used for defining the Rotational Wall Parallel to the Part Line (Rot_Wall_Par_Part_Line) translation mechanism. But in this particular case the value of the co-ordinate of the points $\mathrm{P} 1(\mathrm{x})$ and $\mathrm{P} 2(\mathrm{x})$ are the same and $\mathrm{P} 1(\mathrm{y})$ and $\mathrm{P} 2(\mathrm{y})$ are different. For this reason the external profile will be translated as Cavity Perpendicular Straight Line (Cav_Per_Straight_Line).

\subsection{Translating information from mould design view to the mould manufacturing view}

To translate information between core insert design view and core insert manufacturing view a several points must be considered. This section discusses the importance of them in the context of what information is contained in the core insert design view, which needs be translated in terms of core insert manufacturing in the mould manufacturing view. For this case the authors assume that the core insert has been designed correctly and stored in the product model. Figure 8 illustrates the critical information that must be translated from core design to core manufacturing views. The figure is highlighting the information that must be translated between core insert design to machining in the core insert manufacturing view. 


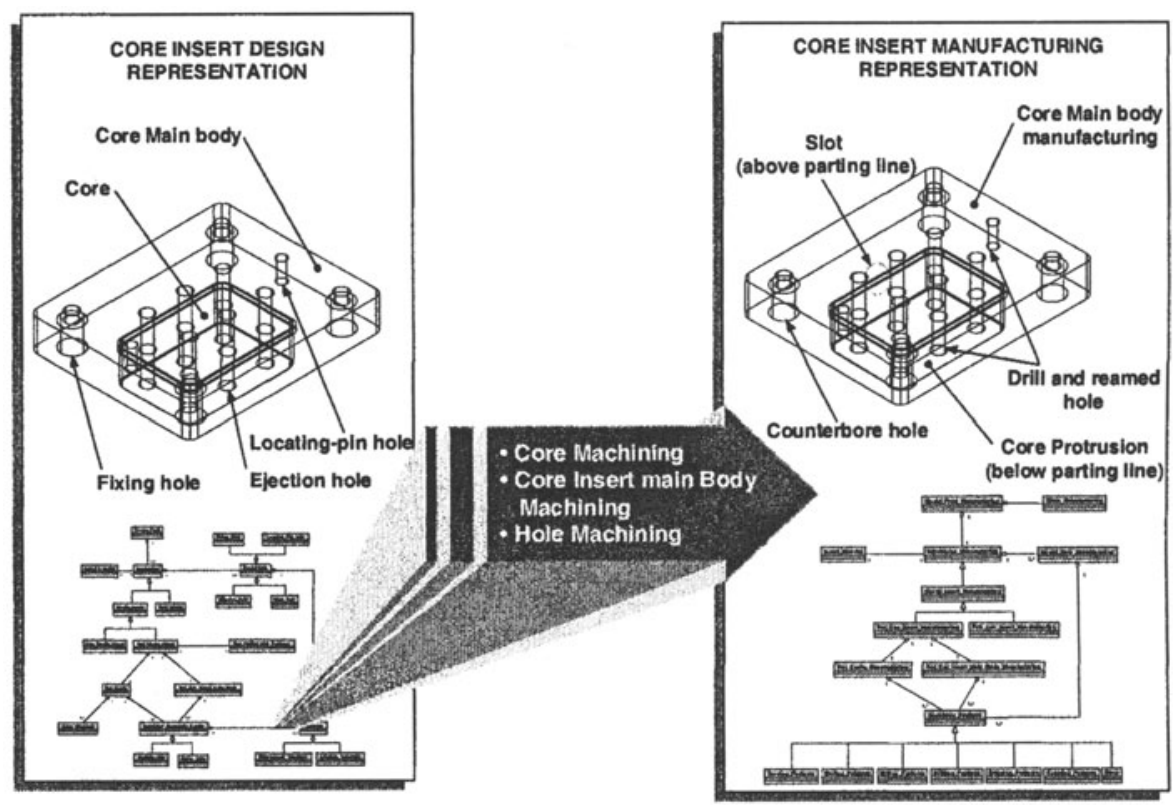

Figure 8. Information to be translated from core insert design view to core insert manufacturing view.

In order to translate the information contained in the Rotational Cavity class to the Rotational Cavity Manufacturing class, using a rotational cavity as an example, the Cavity Individual Geometric Profile class (Cav_Individual_Geometric_Profile) must be converted into a Machining Feature class (Machining_Features). The Individual Geometric Profile has a geometric definition and is associated with the tolerance and the material of the insert. The tolerance information is contained in the class tolerance (Tolerance) and the material of the cavity insert is in the class insert material (Insert_Material). Figure 9 illustrates the information that is contained in the Cavity Individual Geometry Profile class (Cav_Individual_Geometric_ Profile) with its associated tolerance and insert material classes being translated as Machining Features (Machining_Features). This machining feature is associated with the Rotational Cavity class (Rot_Cavity), with the class Tolerance (Tolerance) and the Insert Material class (Insert_Material), being translated as Facing Boring machining feature (Facing_Boring). This translation can be made by considering all the profiles that compound the cavity profile together or by considering each profile individually. The example shown in the figure considers an individual translation. 


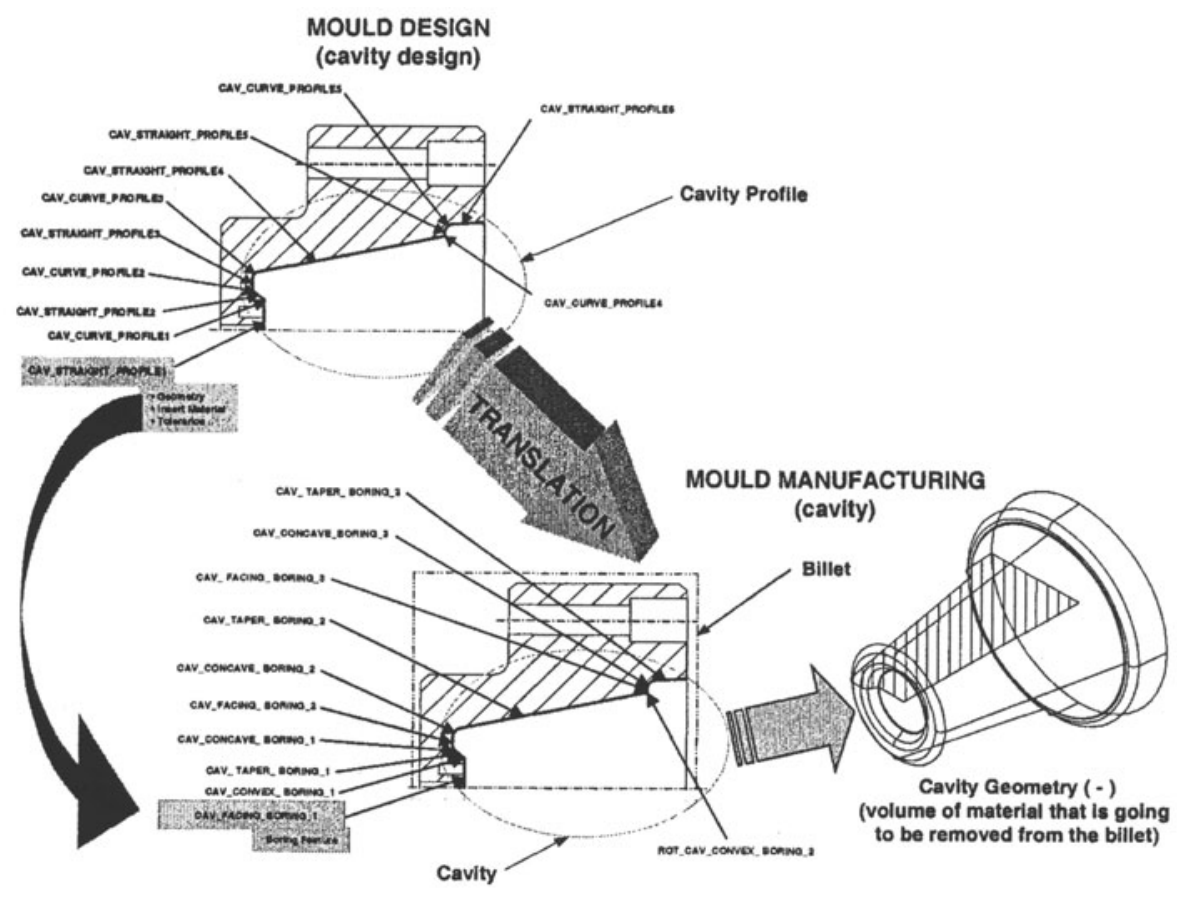

Figure 9. Example of translation of a rotational cavity into a rotational cavity manufacturing.

For a rotational cavity each Cavity Straight Line profile and each Cavity Curve Line profile must be translated in terms of Machining Features (Boring_Features) in order to generate the machining features which are going to machine the cavity. The Cavity Straight Line profiles can be parallels, perpendiculars or tapers to the parting line while the Cavity Curve Line can only be a curve. Whenever the Cavity Straight Line is parallel to the parting line (Cav_Par_Straight_Line), it will be translated as machining feature Facing Boring (Facing_Boring) due to the profile being perpendicular to the axis of revolution of the feature. Whenever the Cavity Straight Line is perpendicular to the parting line (Cav_Per_Straight_Line), it will be translated as a machining feature Horizontal Boring (Horizontal_ Boring) because the profile in this case is perpendicular to the axis of revolution of the feature. If the Cavity Straight Line is tapered to the parting line (Cav_Taper_Straight_Line), it will be translated as machining feature Taper Boring (Taper_Boring). The definition of the translation mechanism of the Cavity Straight Line is illustrated in Figure 10a. 


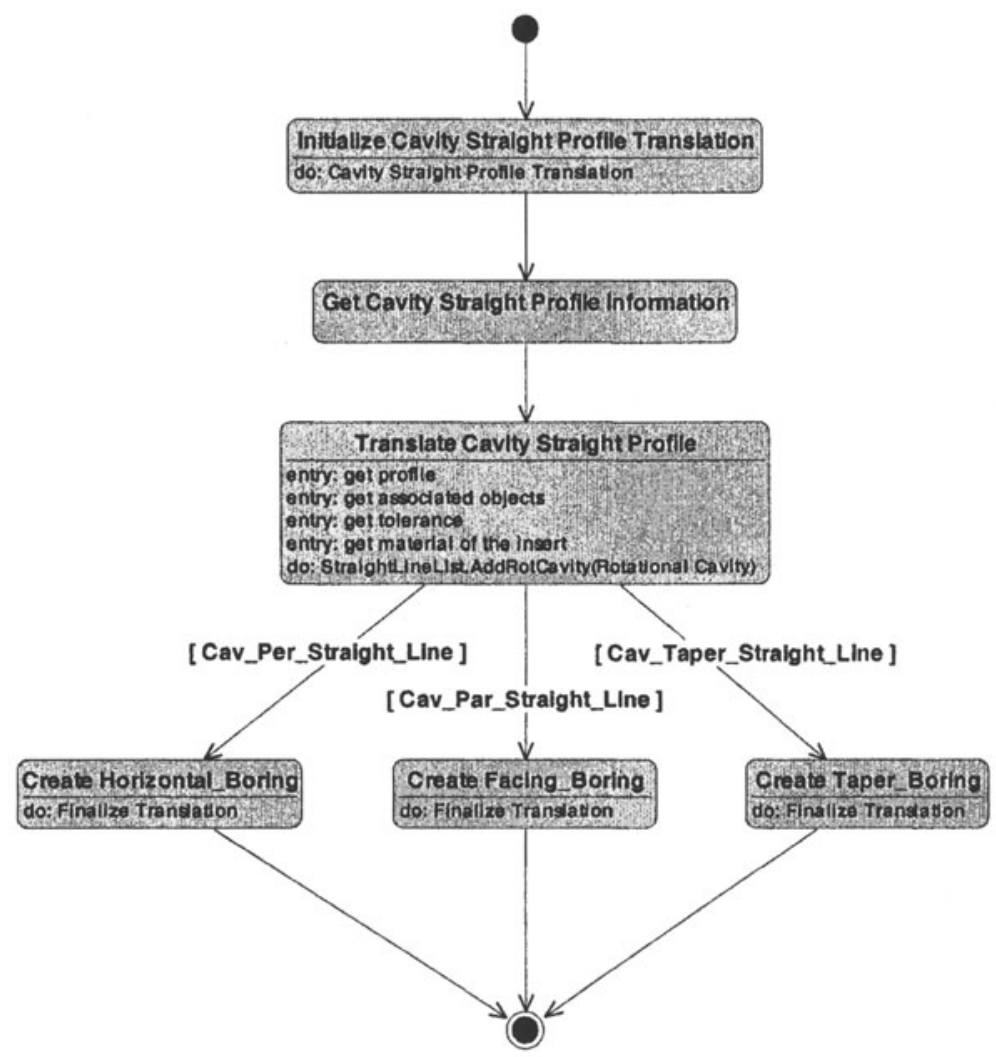

Figure 10a. The definition of the translation mechanism of the Cavity Straight Line

The translation mechanism will initially search the straight profiles in the product model. It will get the profile, the associated objects, tolerance and the material of the insert. Then it will translate each cavity straight profile into facing, horizontal or taper boring using the criteria described at the beginning of this paragraph. To translate cavity curve lines into machining features, it is necessary to convert each Cavity Curve Line (Cav_Curve_Line) into Concave or Convex Boring (Concave_Boring and Convex_Boring) machining features. If the reference angle of the Cavity Curve Line is bigger than 90 and less than 270 degrees the translation mechanism will convert the curved line profile as Convex Boring (Convex_Boring) machining feature, otherwise, it will convert as Concave Boring (Concave_Boring) as illustrated in Figure $10 b$. 


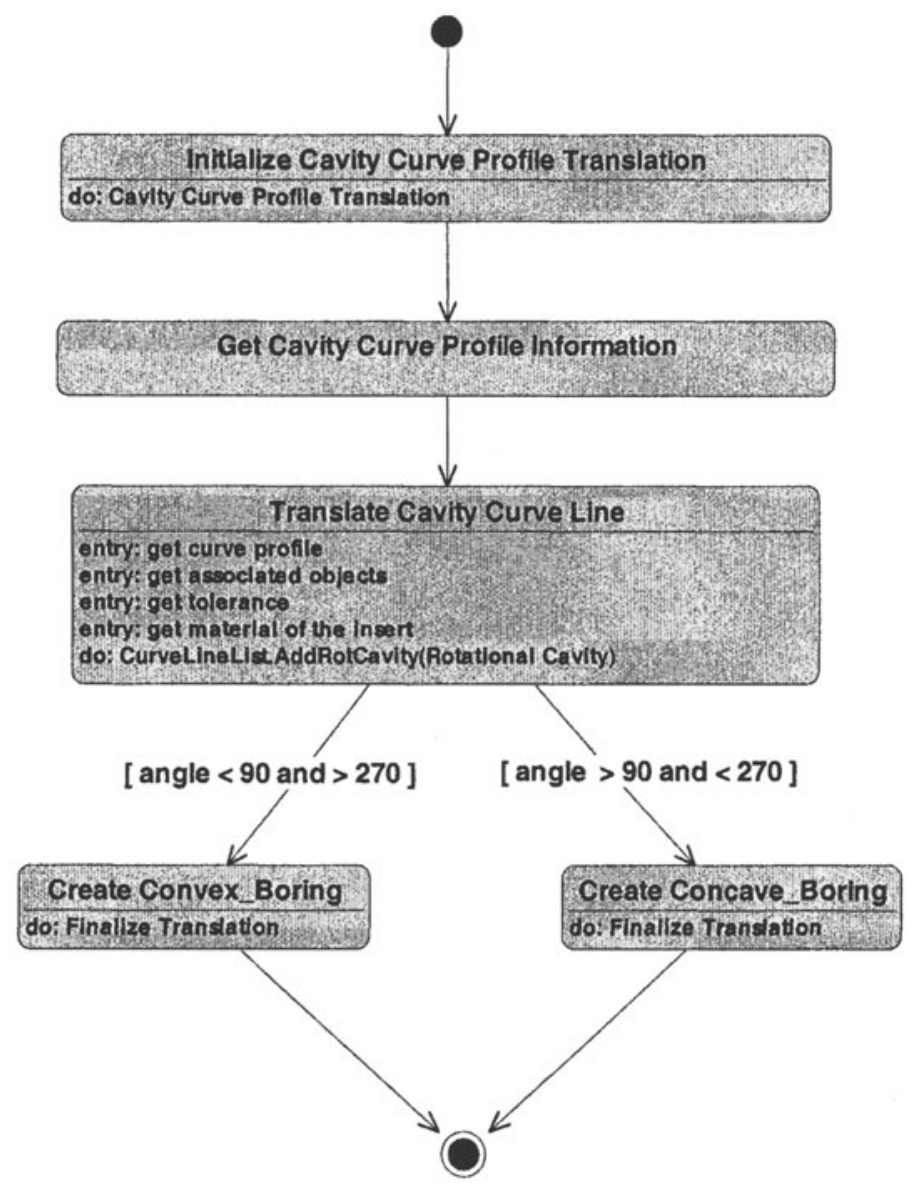

Figure 10b. The definition of the translation mechanism of the Cavity Curve Lines

The mechanism starts by searching for the cavity curve lines in the product model. It will get the curve profile, associated objects, tolerance and material of the insert.

\section{CONCLUDING DISCUSSION}

This paper has focused on the needs of future product design systems which must provide design teams with tools which can offer multi-viewpoint support. The advantages of utilising information modelling approaches and providing databases of information in the form of product and manufacturing models, as a precursor to multi-viewpoint decision support, have been highlighted. The research has shown that it is possible to translate 
information between two views once the relationship between the information between the views has been defined. Depending on the types of relationship the information will either be shared or translated from one form into another. The case of shared information is when the two views use the same piece of information without any change to it. The case of translation is necessary when one view needs the information of the another view and this information must be assigned in another format to that of the original. The translation information is more complex than shared information because the translation mechanisms must have knowledge of the relationships between the two distinct views in order to convert information from one to another. The research has shown how links can be maintained between design views of related products through the plastic part and its mould. It has also shown how links can be maintained between design and manufacture views through consideration of the mould design views and mould machining view. There is a need to extend this work to provide a more comprehensive set of both design views and manufacturing process views. For example functional design views of the plastic product, design views of the mould such as feeding, cooling, ejection and multiple manufacturing views such as EDM, grinding, assembly. The exploration of such a set of views would provide a substantial exploration of the points raised in the paragraph above concerning the likely need to extend the problem beyond a 1:1 translation. There would also be significant value in exploring the research concept against the design and manufacture of alternative, perhaps more complex, types of product other than injection moulded parts.

\section{ACKNOWLEDGEMENTS}

The authors are thankful for the financial support provided by the Brazilian Government Conselho Nacional de Desenvolvimento Científico e Tecnológico (CNPq), Pontifícia Universidade Católica do Paraná (PUCPR) and to the MIM research programme at Loughborough University with which this work was linked. The MIM research programme was funded through EPSRC grant GR/L41493.

\section{REFERENCES}

Al-Ashaab, A.H. (1994), A Manufacturing Model To Capture Injection Moulding Process Capabilities To Support Design For Manufacture, Ph.D. Thesis, Loughborough University, Department of Manufacturing Engineering. 
Allada, V., Anand, S. (1995), Feature-Based Modelling Approaches For Integrated Manufacturing: State-Of-Art And Future Research Directions, Int. Journal Computer Integrated Manufacturing, Vol. 8, Number 6, pp. 411-440.

Boothroyd, G., Dewhurst, P., Knight, W. (1993), Product For Manufacture and Assembly, New York M. Dekker Inc.

Boothroyd, G. (1994) Product design for manufacture and assembly. Computer Aided Design, 26(7), pp. 505-520.

Chin, K.S. and Wong, T.N., Knowledge-based evaluation for the conceptual design development of injection moulding parts. Engng Applic. Artif.Intell., 1996, Vol. 9, No. 4, pp. $359-376$

Fauvel, O.R. (1994) Object-oriented design for manufacture. Journal of Intelligent Manufacturing, Vol.5, pp.1-11.

Fowler J. (1995) - STEP for Data Management, Exchange and Sharing. Technology Appraisals Ltd. - ISBN 1871802369.

Gupta S.K., Regli W.C., Das D. and Nau D. S. (1997) - Automated Manufacturability Analysis: A Survey. Research in Engineering Design, 9, pp.168-190.

Krause F.L., Ciesla M., Rieger E., Stephan M. and Ubrich A. (1995) - Features - Semantic Objects for the Integration of Tasks in the Product Development process. Proceedings of the Computers in Engineering Database Symposium, ASME.

Krause, F.L., Kimura, F., Kjellberg, T., Lu, S.C.Y. (1993) Product Modelling. Annals of the CIRP, Vol. 42/2/1993.

Lee, R.J.V, and Young, R.I.M. (1998) Information supported design for manufacture of injection-moulded rotational products. International Journal of Production Research, Vol. 36, No 12, pp. 3347-3366.

Lee, R.J.V. (1996), A Design For Injection Moulding Strategist In An Information Modelling Environment, Ph.D. Thesis, Loughborough University, Department of Manufacturing Engineering.

Lee, R.S., Chen, Y.M. and Lee, C.Z. (1997) Development of a concurrent mould design system: A knowledge-based approach. Computer Integrate Manufacturing Systems, Vol. 10, No. 4, pp. 287-307.

Pratt M. J., "Application of feature recognition in the product life-cycle", International Journal of Computer Integrating Manufacturing, 6(1-2), pp. 13-19, 1993.

Rosenman, M.A. and Gero, J.S. (1996) Modelling multiple views of design objects in a collaborative design. Computer-Aided Design, Vol. 28, pp.193-205.

Salomons O.W., Van Houten F.J.A.M., and Kais H.J.J. (1993) Review of Research in Feature-Based Design, Journal of Manufacturing Systems, Volume 12/No 2.

Salomons, O.W., Houten, F.J.A.M.V., Kais, H.J.J. (1993), Review Of Research In FeatureBased Design, Journal of Manufacturing Systems, Vol. 12, Number 2, pp. 113-132.

Sanchez, J.M., Priest, J.W. and Soto, R. (1997) Intelligent reasoning assistant for incorporating manufacturability issues into the design process. Expert Systems with Applications, Vol. 12, No. 1, pp. 81-87.

Willems, R., Lecluse, D., Kruth, J.P. (1995), Object Oriented Information Storage For The Design Of Injection Moulds, Knowledge Intensive CAD, Vol. 1, pp. 188-202, Proceedings of First IFIP WG 5.2, Finland.

Wooldridge, M. and Jennings, N. (1995) Intelligent agents: Theory and practice. The Knowledge Engineering Review, Vol. 10, number 2, pp.115-152. 